\section{Evaluating Paradox Walnut Rootstocks for Resistance to Armillaria Root Disease}

\author{
Kendra Baumgartner ${ }^{1}$, Phillip Fujiyoshi, and Greg T. Browne \\ U.S. Department of Agriculture, Agricultural Research Service, Crops \\ Pathology and Genetics Research Unit, One Shields Avenue, Davis, CA 95616 \\ Chuck Leslie \\ University of California, Department of Plant Sciences, Davis, CA 95616
}

Daniel A. Kluepfel

U.S. Department of Agriculture, Agricultural Research Service, Crops Pathology and Genetics Research Unit, One Shields Avenue, Davis, CA 95616

Additional index words. Armillaria mellea, black walnut, clonal rootstocks, Juglans regia, Pterocarya stenoptera

Abstract. The most common rootstock for Juglans regia (Persian or "English" walnut) in California is Paradox, typically a hybrid of $J$. hindsii (Northern California black walnut) $\times$ $J$. regia. Unfortunately, Paradox is very susceptible to Armillaria root disease. The relative resistance to Armillaria mellea of six clonally propagated Paradox rootstocks (AX1, Px1, RR4 11A, RX1, Vlach, VX211) was evaluated and compared with that of clonally propagated $J$. hindsii rootstock selection W17, J. regia scion cultivar Chandler, and Pterocarya stenoptera (Chinese wingnut). In a growth-chamber assay, plants were micropropagated and rooted in vitro before inoculating the culture medium with $A$. mellea. At two months post-inoculation, the most resistant and susceptible Paradox rootstocks were AX1 and VX211, respectively, with $9 \%$ vs. $70 \%$ mortality, and this finding was consistent across three isolates of $A$. mellea and three replicate experiments. This broad range of resistance within Paradox is consistent with past field trials that tested other genotypes. Our finding of similarly high susceptibility of 'Chandler' and W17 (61\% vs. 69\% mortality) is in contrast to two field trials, in which other $J$. regia genotypes were more susceptible than those of $J$. hindsii. A third trial, however, identified some $J$. regia genotypes as more resistant than those of $J$. hindsii. Therefore, it is possible that W17, which was not previously tested, is an Armillaria-susceptible genotype of $J$. hindsii. Based on our findings of repeatable mortality levels across three isolates of $A$. mellea and three replicate experiments, the growth-chamber assay has promise, albeit with confirmed resistant and susceptible controls, for identifying putative resistant rootstocks (e.g., AX1) in preparation for a field trial with controlled inoculations.

Armillaria root disease affects orchards in all Juglans regia (Persian walnut)-growing regions of California (Gardner and Raabe, 1963). The causal agent is Armillaria mellea (Basidiomycota, Physalacriaceae), which attacks walnut and other woody perennial horticultural crops (e.g., stonefruits) (Baumgartner et al., 2011). The pathogen kills and then decays woody roots, which in turn reduces crop yield and growth (Baumgartner, 2004), inhibits nutrient and water uptake (Baumgartner and Warnock, 2006), and eventually kills infected

Received for publication 12 Sept. 2012. Accepted for publication 30 Nov. 2012.

This research was funded by a grant to Daniel Kluepfel (PI) from the California Department of Food and Agriculture.

We gratefully acknowledge pre-submission review of this manuscript by J. Preece (USDA-ARS, Davis, CA) and B. Wood (USDA-ARS, Byron, GA) and laboratory assistance for plant propagation from Morgan McMahon.

${ }^{1}$ To whom reprint requests should be addressed; e-mail kbaumgartner@ucdavis.edu.
$J$. hindsii (Northern California black walnut) and $J$. regia, which is more vigorous, more resistant to some Phytophthora species, and more tolerant of soil salinity than $J$. regia (McGranahan and Catlin, 1987). Despite its widespread use, the resistance of Paradox rootstock to Armillaria root disease, crown gall, and Phytophthora crown and root rot is insufficient as evidenced by serious losses to the walnut industry from these root diseases (McGranahan and Leslie, 1990). Breeding efforts have focused on identifying sources of resistance among $J$. hindsii and other wild species of black walnut and crossing them with $J$. regia to develop new clonally propagated, disease-resistant Paradox rootstocks (Hackett et al., 2010). For example, RX1 (J. microcarpa $\times J$. regia) is resistant to Phytophthora crown and root rot (Browne et al., 2010). A transgenic approach has also been used (Hackett et al., 2010), specifically to engineer rootstocks for RNAi-mediated resistance to crown gall (e.g., RR4 11A). However, there are no reports of identified resistance to $A$. mellea from controlled inoculations of J. regia, J. hindsii, or Paradox rootstocks in the greenhouse or field.

Field trials for Armillaria species require controlled inoculations after plants are established and then $\approx 10$ years for sufficient evaluation (e.g., Guillaumin et al., 1989). To identify the most promising sources of resistance before establishing such trials, it is therefore critical to have a rapid and reliable screening assay. A slow and unreliable greenhouse assay has been a barrier to identification of Armillaria-resistant rootstocks for many fruit and nut crops despite repeated attempts at improvement by numerous scientists over the course of many decades (Baumgartner and Rizzo, 2006; Raabe, 1979; Thomas et al., 1948). A. mellea grows so slowly that the initial stages of the assay (inoculum preparation, establishment of infection) take one year (Redfern and Filip, 1991). The inoculum, which consists of wood fragments colonized by the pathogen, contains variable concentrations of mycelium and is surprisingly shortlived in the greenhouse, sometimes dying before an infection is established. This results in unequal challenge among replicate plants, which in turn confounds detection of differences between rootstocks. Furthermore, the greenhouse assay does not bring about repeatable symptoms or mortality (Singh, 1980). Without such measures of resistance, therefore, there are no quantifiable means of comparing rootstocks.

As an alternative to the unreliable greenhouse assay, we used a growth-chamber assay originally developed for grape (Baumgartner et al., 2010) for walnut plants micropropagated in a culture medium that supported both host and pathogen. Our objective was to evaluate six clonally propagated Paradox rootstocks (AX1, Px1, RX1, RR4 11A, VX211, Vlach) for resistance to Armillaria root disease. Paradox rootstocks were compared with a $J$. hindsii selection, W17, and a $J$. regia scion cultivar, Chandler, which are presumed to be Armillaria-resistant and 
Armillaria-susceptible, respectively, based on one field trial in which seedlings of both species, albeit different genotypes than W17 and 'Chandler', were planted in an orchard with a history of Armillaria root disease (Hendricks et al., 1978). In addition, the Juglans relative Pterocarya stenoptera (Chinese wingnut) was included for comparison, which is highly resistant to P. cinnamomi and $P$. citricola, and is thus used as a resistant control in screening for Phytophthora resistance (Browne et al., 2011).

\section{Materials and Methods}

Plant propagation and inoculation. Plant genotypes were selected in part based on consistent rooting in vitro and their known or putative levels of resistance to other root pathogens, as reported from past studies (Table 1). We evaluated six clonally propagated Paradox genotypes (AX1, Px1, RX1, RR4 11A, VX211, Vlach), one clonally propagated, putative source of Armillaria resistance, $J$. hindsii selection $\mathrm{W} 17$, and one clonally propagated, putative source of susceptibility, J. regia cultivar Chandler. Also included for comparison was one clonally propagated selection of $P$. stenoptera (also known as ' $\mathrm{WN} \times \mathrm{W}$ ', although it is not a hybrid).

Three replicate experiments were conducted with plants for each experiment propagated four months apart and incubated under the same controlled conditions [ 25 to $27{ }^{\circ} \mathrm{C}$, 16-h photoperiod provided by cool white fluorescent light (F72T12/CW/VHO; Philips Lighting Company, Sommerset, NJ) that provided a photon flux of $\left.40 \mu \mathrm{mol} \cdot \mathrm{m}^{-2} \cdot \mathrm{s}^{-1}\right]$. The plantlets were derived from micropropagated shoot cultures multiplied and rooted in vitro on Driver Kuniyuki Walnut medium (DKW) in Magenta Corp. GA7 containers $(75 \times 75 \times$ $100 \mathrm{~mm}$ ) according to the method of Leslie et al. (2010). Briefly, microshoot cultures of each genotype were maintained on DKW
(1 mg. $\mathrm{L}^{-1}$ 6-benzylaminopurine, $0.01 \mathrm{mg} \cdot \mathrm{L}^{-1}$ indole-3-butyric acid) in the dark as etiolated shoots, except for W17 and P. stenoptera, which do not grow well in the dark and so were maintained in the light as green shoots. Etiolated and green shoots cut from these cultures were induced to root on DKW with $25 \mu \mathrm{M}$ salt of indole-3-butyric acid for $7 \mathrm{~d}$ in the dark and then transferred to DKW basal medium (i.e., without hormones) in the light until roots appeared, at which point plants were carefully transferred to individual GA7 containers with fresh DKW basal medium. Plants were grown for $14 \mathrm{~d}$ until there were at least three 1-cm-long roots for inoculation.

Three isolates of $A$. mellea were used separately to inoculate all nine plant genotypes in each of the three experiments. Two isolates, $\mathrm{CC} 7$ and SJ1, were recovered from symptomatic walnut (Contra Costa County, CA, and San Joaquin County, CA, respectively). From our collection of $12 \mathrm{~A}$. mellea isolates from walnut, these two isolates exhibited similar growth in culture (data not shown). The third isolate, Son3, was recovered from a symptomatic grapevine in Sonoma County, CA, and was examined in a previous experiment screening grape rootstocks from Armillaria resistance using similar propagation and inoculation techniques (Baumgartner et al., 2010). Inoculum was prepared by homogenizing an $A$. mellea isolate grown in potato dextrose broth (PDB) with $2.5 \mathrm{~mm}$ sodium acetate $\left(7 \mathrm{~d}, 25^{\circ} \mathrm{C}, 100 \mathrm{rpm}\right)$ for $30 \mathrm{~s}$ and then transferring with a sterile $1-\mathrm{mL}$ glass pipette $100 \mu \mathrm{L}$ of the resulting homogenate (i.e., mycelial fragments) per plant onto the surface of the DKW medium. Non-inoculated controls were inoculated with $100 \mu \mathrm{L}$ sterile PDB. In this way, there were four inoculation treatments: CC7, SJ1, Son3, and non-inoculated controls. In a preliminary experiment using this technique to inoculate Vlach, also propagated as described previously, we found the entire layer of DKW basal medium $(\approx 2 \mathrm{~cm}$ thick) became colonized by A. mellea at 2 weeks post-inoculation and that the first plants began to succumb to infection at one month post-inoculation. In the same preliminary experiment, non-inoculated Vlach showed symptoms of nutrient deficiency at two months post-inoculation, at which point it seemed logical to stop evaluations of Armillaria resistance.

For each of the three experiments, there were 15 replicate plants per plant genotype $X$ inoculation treatment combination (nine plant genotypes $x$ four inoculation treatments $\times$ 15 replicate plants $=540$ total plants per experiment). Our measure of resistance was percent mortality, calculated as the proportion of inoculated plants that died within two months post-inoculation out of the total number inoculated. Confirmation of infection was based on recovery of the pathogen in culture. At the time of mortality, roots were carefully separated from the DKW basal medium by submerging the root system embedded within the medium in sterile water to break the medium into smaller pieces and then using a forceps to gently pull roots from pieces of medium. For confirmation of infection, four root tips per plant were plated on water agar within $2 \mathrm{~d}$ of plant mortality. On the same day, positive controls of each of the three A. mellea isolates were also plated on water agar for comparison. After $10 \mathrm{~d}$ of incubation at $25{ }^{\circ} \mathrm{C}$, cultures were examined for $A$. mellea colonies with the following characteristics: colony diameter of $\approx 2 \mathrm{~cm}$, regular colony margin, clampless hyphae embedded in the agar, sparse white aerial hyphae, absence of spores/spore-bearing structures, and the possible presence of immature rhizomorphs (white when embedded in the agar, black when above the surface). Root tips gathered from non-inoculated plants were examined in this same manner on the day of inoculation and at two months post-inoculation

Table 1. Parentage of clonally propagated walnut and wingnut genotypes inoculated with Armillaria mellea, and their resistance/susceptibility to other root diseases, as determined by previous controlled inoculations with the associated pathogens.

\begin{tabular}{|c|c|c|c|c|}
\hline \multirow[b]{2}{*}{ Plant genotype } & \multirow[b]{2}{*}{ Parentage $^{z}$} & \multicolumn{3}{|c|}{ Relative resistance to root diseases of walnut } \\
\hline & & $\begin{array}{c}\text { Crown gall, } \\
\text { Agrobacterium tumefaciens } \\
\text { (Hackett et al., 2010) }\end{array}$ & $\begin{array}{l}\text { Phytophthora crown and root } \\
\text { rot, Phytophthora cinnamomi and } \\
\text { P. citricola (Browne et al., 2010) }\end{array}$ & $\begin{array}{l}\text { Root-knot nematode, } \\
\text { Meloidogyne incognita } \\
\text { (Buzo et al., 2009) }\end{array}$ \\
\hline \multicolumn{5}{|c|}{ Paradox rootstocks } \\
\hline AX1 & $\begin{array}{l}\text { Juglans californica } \\
\quad \text { DJUG } 23.20^{\mathrm{y}} \times J \text {. regia } \text { O.P. }\end{array}$ & Moderately resistant & Susceptible & Higher densities \\
\hline RX1 & J. microcarpa DJUG29.11 $1^{\mathrm{y}} \times$ J. regia O.P. & Moderately resistant & Moderately resistant & - \\
\hline Px1 & J. hindsii 'Rawlins' $\times$ J. regia O.P. & Susceptible & Susceptible & Better host \\
\hline Vlach & $J$. hindsii (unknown female) $\times J$. regia O.P. & Moderately resistant & Susceptible & Poorer host \\
\hline RR4 11 $\mathrm{A}^{\mathrm{x}}$ & J. hindsii 'Rawlins' $\times$ J. regia O.P. & Immune & - & - \\
\hline VX211 & $\begin{array}{l}\text { J. hindsii (confidential nursery source) } \times \\
\text { J. regia O.P. }\end{array}$ & Moderately resistant & Moderately resistant & Poorer host \\
\hline \multicolumn{5}{|c|}{ Northern California black walnut rootstock } \\
\hline W17 & J. hindsii & Susceptible & Susceptible & - \\
\hline \multicolumn{5}{|c|}{ Persian walnut scion } \\
\hline $\begin{array}{c}\text { 'Chandler' } \\
\text { Chinese wingnu }\end{array}$ & J. regia 'Pedro' $\times$ J. regia 'UC 56-224' & Resistant & Susceptible & - \\
\hline $\begin{array}{l}\text { Pterocarya } \\
\text { stenoptera }\end{array}$ & $\begin{array}{l}\text { Pterocarya stenoptera ' } \mathrm{WN} \times \mathrm{W} \text { ' } \\
\text { DPTE10.05' }\end{array}$ & Resistant & Highly resistant & - \\
\hline
\end{tabular}

${ }^{\mathrm{z} O . P .}=$ open-pollinated (i.e., unknown male parent of the species indicated).

${ }^{y}$ Accession from the U.S. Department of Agriculture, Agricultural Research Service, National Clonal Germplasm Repository.

${ }^{\mathrm{x}}$ Transgenic rootstock, engineered for resistance to the causal bacterium of crown gall, Agrobacterium tumefaciens (Hackett et al., 2010). 
in each of the three experiments $(n=$ five plants per genotype per experiment).

Statistical analyses. Analysis of variance (ANOVA) was used to determine the effects of the independent experiments (i.e., 1, 2, or 3), plant genotype (AX1, Px1, RX1, RR4 11A, VX211, Vlach, 'Chandler', W17, or $P$. stenoptera), inoculation treatment (CC7, SJ1, Son3, or non-inoculated), and their interactions on percent mortality. ANOVA was performed using the MIXED procedure in SAS (SAS Institute Inc., Cary, NC) with KenwardRoger as the denominator df method (Littell et al., 1996). All main and interaction effects were considered fixed effects. $F$ values with $P<0.05$ were considered significant. Before ANOVA, homogeneity of variance across treatments was confirmed (Box et al., 1978). After ANOVA, for significant effects $(P<$ $0.05)$, differences among means were assessed based on the presence/absence of overlap of their $95 \%$ confidence intervals, and means without overlapping intervals were considered significantly different (Westfall et al., 1999).

\section{Results}

Among all inoculated plants, the entire DKW basal medium was colonized by $A$. mellea by 2 weeks post-inoculation based on the presence of the mycelium in the medium as viewed from the base of each Magenta box. At one month post-inoculation, between one and 10 replicate plants succumbed to infection for each plant genotype, except for Paradox rootstock AX1, for which the first plants did not succumb to infection until after one month post-inoculation (Table 2). The pathogen was recovered in culture from roots of all inoculated plants either at the time of mortality (for plants that succumbed to infection within two months post-inoculation) or at two months post-inoculation (for plants that survived). The pathogen was absent from all plants examined on the day of inoculation and was also absent from all non-inoculated plants examined at two months post-inoculation based on the inability to recover $A$. mellea from roots plated on water agar (data not shown). None of the non-inoculated plants showed symptoms or died at any point during any of the three experiments.
ANOVA identified significant differences in percent mortality between plant genotypes $(P<0.0001)$. There were no significant main or interaction effects of experiment $(P$ values all $\geq 0.20$ ) nor were there significant main or interaction effects of $A$. mellea isolate ( $P$ values all $\geq 0.07$ ). As such, our findings were consistent across three replications of the experiment and among all three isolates of $A$. mellea. The plant genotype with the lowest level of mortality was Paradox rootstock AX1 with mortality of $9.25 \%$ at two months post-inoculation $(\mathrm{n}=135$ plants, summed across all three isolates and all three experiments; Table 2). AX1 had significantly lower percent mortality than VX211, which had the highest percent mortality among all six Paradox rootstocks $(61.11 \%$ mortality; $\mathrm{n}=135$ plants, summed across all three isolates and all three experiments). After two months, depending on the isolate of $A$. mellea, there were only three to five dead AX1 plants out of 45 inoculated. This is in contrast to an average of 25 to 41 dead VX211 plants out of 45 inoculated. AX1 also had significantly lower percent mortality than the non-Paradox genotypes, 'Chandler', W17, and P. stenoptera. Throughout each of the three experiments, replicate plants of AX1, Px1, RX1, and Vlach that survived infection had relatively healthy-looking foliage (Fig. 1). Stunting and wilting at two months post-inoculation was more evident in RX1 and Vlach than in AX1 and Px 1 .

There were relatively consistent levels of mortality for AX1, W17, and P. stenoptera among plants inoculated with the three isolates of A. mellea (Table 2). For these three plant genotypes, percent mortality varied among isolates within a genotype by $3.9 \%$, $5.6 \%$, and $6.4 \%$, respectively. In contrast, variation among isolates was greater for VX211 and RR4 11A (34.85\% and 42.42\%, respectively), although these differences were not significant based on the results of ANOVA (main and interaction effects of isolate with $P$ values $\geq 0.07$ ).

\section{Discussion}

AX1 had the lowest percent mortality of all nine walnut rootstocks, and this finding was consistent for three isolates of A. mellea and in three replicate experiments. Our finding of significantly greater resistance of AX1 than VX211 may reflect the different maternal parents of these Paradox rootstocks (J. californica and $J$. hindsii, respectively). The broad range of resistance that we found among six clonally propagated Paradox rootstocks, $9 \%$ vs. $70 \%$ mortality $(\mathrm{n}=135$ plants per rootstock, averaged across isolates and experiments), is consistent with past field trials, in which other genotypes were tested. In one field trial, among seedlings from six different seed sources of Paradox, mortality ranged from $0 \%$ to $25 \%$ ( $\mathrm{n}=$ five to 20 trees per rootstock) and was similar to that of seedlings from three cultivars of $J$. regia, which ranged from $5 \%$ to $23 \%(n=20$ to 40 trees per rootstock; Reil, 1997). Two other field trials had contrasting findings for the relative resistance of Paradox, which was found to be either Armillaria-susceptible (61\% seedlings infected) (Hendricks et al., 1978) or Armillaria-resistant (0\% mortality) (Teviotdale and Sibbett, 1999), relative to $J$. regia. As such, not all Paradox genotypes are more resistant than those of J. regia.

The growth-chamber assay brought about reliable infection of all inoculated plants and repeatable mortality levels across different isolates of $A$. mellea and replicate experiments. Because all three experiments were conducted in the course of one year, this assay may serve as a screening technique for narrowing the list of candidate rootstocks for a long-term field trial. The greenhouse assay for A. mellea, in which the plant is rooted in a soil-based medium and the inoculum consists of infected wood buried in the soil, certainly appears to mimic the natural state of infection in the field. In practice, however, it is demonstrably slow and unreliable for comparing walnut rootstocks (Thomas et al., 1948). Nonetheless, despite the rapid and reliable qualities of the growth-chamber assay, it may better reflect certain aspects of resistance than others. For example, it may not accommodate the possible effects of root vigor on resistance, because all root surfaces are completely surrounded by the pathogen, hence the need for a field trial with controlled inoculations to confirm the resistance of AX1. An environment in which a root system can develop naturally may evaluate a broader

Table 2. Percent mortality of each plant genotype between zero and two months post-inoculation for each of three isolates of $A$. $m e l l e a(C C 7$, SJ1, Son3) versus non-inoculated controls. ${ }^{\mathrm{z}}$

\begin{tabular}{|c|c|c|c|c|c|c|c|c|c|c|c|c|}
\hline \multirow[b]{3}{*}{ Plant genotype } & \multicolumn{12}{|c|}{ Percent mortality per inoculation treatment } \\
\hline & \multicolumn{4}{|c|}{ Zero to one month post-inoculation } & \multicolumn{4}{|c|}{ One to two months post-inoculation } & \multicolumn{4}{|c|}{ Total $^{\mathrm{y}}$} \\
\hline & CC7 & SJ1 & Son3 & Non-inoculated & $\mathrm{CC} 7$ & SJ1 & Son3 & Non-inoculated & $\overline{\mathrm{CC} 7}$ & SJ1 & Son3 & Non-inoculated \\
\hline$\overline{\mathrm{AX} 1}$ & 0 & 0 & 0 & 0 & 7 & 10 & 11 & 0 & $7 \mathrm{a}$ & $10 \mathrm{a}$ & $11 \mathrm{a}$ & 0 \\
\hline RX1 & 3 & 7 & 14 & 0 & 22 & 38 & 17 & 0 & $25 \mathrm{ab}$ & $45 \mathrm{ab}$ & $31 \mathrm{ab}$ & 0 \\
\hline Px1 & 12 & 3 & 3 & 0 & 24 & 27 & 21 & 0 & $36 \mathrm{ab}$ & $30 \mathrm{ab}$ & $24 \mathrm{ab}$ & 0 \\
\hline Vlach & 7 & 10 & 19 & 0 & 35 & 25 & 35 & 0 & $42 \mathrm{ab}$ & $35 \mathrm{ab}$ & $54 \mathrm{bc}$ & 0 \\
\hline RR4 11A & 9 & 12 & 24 & 0 & 27 & 20 & 39 & 0 & $36 \mathrm{ab}$ & $32 \mathrm{ab}$ & $63 \mathrm{bc}$ & 0 \\
\hline VX211 & 15 & 6 & 27 & 0 & 47 & 50 & 64 & 0 & $62 \mathrm{bc}$ & $56 \mathrm{bc}$ & $91 \mathrm{bc}$ & 0 \\
\hline W17 & 40 & 26 & 54 & 0 & 26 & 40 & 18 & 0 & $66 \mathrm{bc}$ & $66 \mathrm{bc}$ & $72 \mathrm{bc}$ & 0 \\
\hline 'Chandler' & 20 & 17 & 7 & 0 & 50 & 40 & 50 & 0 & $70 \mathrm{bc}$ & $57 \mathrm{bc}$ & $57 \mathrm{bc}$ & 0 \\
\hline P. stenoptera & 35 & 31 & 64 & 0 & 48 & 57 & 25 & 0 & $83 \mathrm{bc}$ & $88 \mathrm{bc}$ & 89 bc & 0 \\
\hline
\end{tabular}

${ }^{\mathrm{z}}$ Each cell is the mean of 45 observations, averaged across three replicate experiments $(\mathrm{n}=15$ plants per inoculation treatment $\times$ plant genotype, per experiment).

${ }^{\mathrm{y}}$ Means in the same column with different letters are significantly different, based on lack of overlap of their $95 \%$ confidence intervals $(P<0.05)$. 


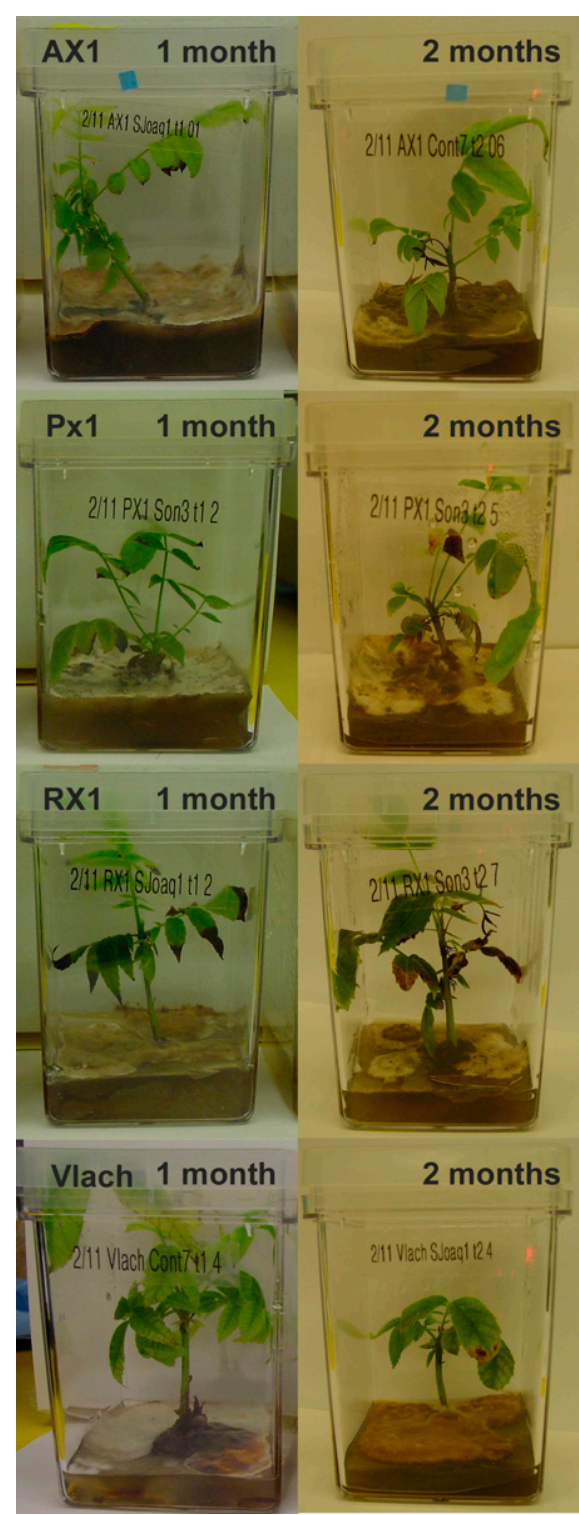

Fig. 1. Paradox rootstocks with the highest levels of resistance (i.e., lowest levels of mortality) to A. mellea. Images are representative of a subset of four Paradox rootstocks (AX1, Px1, RX1, and Vlach) at one and two months post-inoculation during the first of three replicate experiments. The pathogen is visible on the surface of the tissue-culture medium as white- to tan-colored aerial mycelium.

range of factors of resistance than agar-based medium that is saturated by $A$. mellea mycelium.

It is important to keep in mind that all past field trials on walnut in California were conducted in infected orchards without controlled inoculations (Hendricks et al., 1978; Mircetich et al., 1998; Reil, 1997; Teviotdale and Sibbett, 1999). The inoculum of $A$. mellea is not uniformly distributed in field soil (Baumgartner and Rizzo, 2002). Without inoculation, therefore, it is difficult to verify that all plants are equally challenged (i.e., inoculated with the same inoculum concentration at the same time). The mere presence of inoculum is insufficient, as experiments in field soil with artificial inoculum have shown (e.g., Guillaumin et al., 1989). The percentage of plants that become infected and the course of symptom development can vary significantly depending on the levels of inoculum and on the distance between healthy roots and the depth at which inoculum is buried in the soil (Redfern and Filip, 1991). Without inoculation, one can maximize the probability of infection by planting study trees in place of dead/symptomatic trees. However, roots may encounter inoculum and then become infected at different times. Furthermore, plants that "escape" infection because they were not planted near inoculum may be incorrectly categorized as resistant, especially if they are never examined for signs of the pathogen. Lastly, the slow-growing habit of A. mellea means that foliar symptoms and mortality (i.e., measures of resistance) are unlikely to develop within several years of infection. Indeed, the few published field trials with controlled inoculations were carried out for at least 10 years (for e.g., for stonefruits; Guillaumin et al., 1989).

Our finding of similarly high susceptibility of genotypes of J. hindsii and J. regia is in contrast to past reports from two field trials. Past field trials did not test W17 or 'Chandler', but instead other genotypes (seedlings from different seed sources, specifically) of $J$. hindsii and $J$. regia, so at best we can make comparisons at the plant-species level. Teviotdale and Sibbett (1999) determined, at four years after planting $(\mathrm{n}=10$ trees per rootstock), that $J$. hindsii was more resistant ( $0 \%$ mortality) relative to $J$. regia 'Sunland' (20\% mortality). Similarly, Hendricks et al. (1978) determined, at six years after planting (neither sample sizes nor mortality rates reported, however), that $J$. hindsii from one seed source had a much lower rate of infection (24\%) compared with J. regia 'Eureka' (71\%). A third field trial by Reil (1997) demonstrated overlapping ranges of resistance within each species in evaluating seedlings from multiple cultivars of $J$. regia and more than one seed source of J. hindsii. At 10 years after planting, the resistance of three $J$. regia cultivars ranged from $5 \%$ to $23 \%$ mortality for 'Amigo' ( $\mathrm{n}=20$ trees) vs. 'Manregian' ( $n=40$ trees), respectively. The two seed sources of $J$. hindsii had only a slightly lower range of mortality: $1 \%$ to $15 \%$ ( $\mathrm{n}=20$ to 40 trees per rootstock). Nonetheless, some seed sources of $J$. hindsii were more susceptible than $J$. regia. Therefore, it is possible that W17 is a susceptible genotype of $J$. hindsii and, thus, should not be used as a putative-resistant control in future growth-chamber assays.

No single walnut rootstock is likely to solve all root-disease problems. AX1, which was the most Armillaria-resistant Paradox rootstock, has exhibited high levels of susceptibility to $P$. cinnamomi and $P$. citricola in greenhouse evaluations (Browne et al., 2010). VX211, which was the most Armillaria-susceptible Paradox rootstock, is very tolerant of both Meloidogyne incognita (root-knot nematode) and Pratylenchus vulnus (lesion nematode) (Buzo et al., 2009). For management of
Armillaria root disease, therefore, rootstock selection may not be the best single strategy given that none of the plant genotypes we evaluated were immune to infection by $A$. mellea. Certainly, pre-plant sanitation is important in orchards with a history of Armillaria root disease. Measures that reduce residual root concentrations, either through soil fumigation or ripping the soil to bring the largest residual roots (i.e., the greater sources of substrate) to the surface for removal, will minimize the chances of infection. However, because there are also no effective postinfection controls, a continued focus on identifying Armillaria-resistant walnut rootstocks, using the approach reported here, may identify rootstocks that resist not only this pathogen, but also additional root pathogens.

\section{Literature Cited}

Baumgartner, K. 2004. Root collar excavation for postinfection control of Armillaria root disease of grapevine. Plant Dis. 88:1235-1240.

Baumgartner, K., R. Bhat, and P. Fujiyoshi. 2010. A rapid infection assay for Armillaria and realtime PCR quantitation of the fungal biomass in planta. Fungal Biol. 114:107-119.

Baumgartner, K., M.P.A. Coetzee, and D. Hoffmeister. 2011. Secrets of the subterranean pathosystem of Armillaria. Mol. Plant Pathol. 12:515-534.

Baumgartner, K. and D.M. Rizzo. 2002. Spread of Armillaria root disease in a California vineyard. Amer. J. Enol. Viticult. 53:197-203.

Baumgartner, K. and D.M. Rizzo. 2006. Relative resistance of grapevine rootstocks to Armillaria root disease. Amer. J. Enol. Viticult. 57:408414.

Baumgartner, K. and A.E. Warnock. 2006. A soil inoculant inhibits Armillaria mellea in vitro and improves productivity of grapevines with root disease. Plant Dis. 90:439-444.

Bliss, D.E. 1951. The destruction of Armillaria mellea in citrus soils. Phytopathology 41:665-683.

Box, G.E.P., W.G. Hunter, and J.S. Hunter. 1978. Statistics for experimenters: An introduction to design, data analysis, and model building. Wiley, New York, NY

Browne, G.T., J.A. Grant, L.S. Schmidt, C.A. Leslie, and G.H. McGranahan. 2011. Resistance to Phytophthora and graft compatibility with Persian walnut among selections of Chinese wingnut. HortScience 46:371-376.

Browne, G.T., L.S. Schmidt, R. Bhat, C.A. Leslie, W. Hackett, B. Beede, and J. Hasey. 2010. Etiology and management of crown and root rots of walnut, Walnut Research Reports. California Walnut Board. p. 225-236.

Buzo, T., J. McKenna, S. Kaku, S.A. Anwar, and M.V. McKenry. 2009. VX211, a vigorous new walnut hybrid clone with nematode tolerance and a useful resistance mechanism. J. Nematol. 41:211-216.

Gardner, M.W. and R.D. Raabe. 1963. Early references to Armillaria root rot in California. Plant Dis. Rptr. 47:413-415.

Guillaumin, J.J., J. Pierson, and C. Grassely. 1989. The susceptibility of different Prunus species used as stone fruit rootstocks to Armillaria mellea (sensu stricto). Seventh International Conference on Root and Butt Rots, Vernon and Victoria, British Columbia, Canada. p. 197-207.

Hackett, W., C. Leslie, J. Grant, B. Lampinen, G. McGranahan, K. Anderson, B. Bob, R. Buchner, 
J. Caprile, C. DeBuse, J. Hasey, N. Manterola, R. Robinson, D. Kluepfel, G. Browne, and M. McKenry. 2010. Clonal propagation of walnut rootstock genotypes for genetic improvement, Walnut Research Reports. California Walnut Board. p. 65-83.

Hendricks, L., P. LaVine, J. Mircetich, and D. Ramos. 1978. Differential susceptibility of walnut rootstocks to Armillaria root rot, Walnut Research Reports. California Walnut Board. p. 4.

Leslie, C.A., W.P. Hackett, and G.H. McGranahan. 2010. Improved rooting methods for walnut (Juglans) microshoots. Acta Hort. 861:365-372.

Littell, R.C., G.A. Milliken, W.W. Stroup, and R.D. Wolfinger. 1996. SAS system for mixed models. SAS Institute Inc., Cary, NC.

McGranahan, G.H. and P.B. Catlin. 1987. Juglans rootstocks, p. 411-450. In: Rom, R.C. and R.F. Carlson (eds.). Rootstocks for fruit crops. John Wiley and Sons, New York, NY.
McGranahan, G.H. and C.A. Leslie. 1990. Walnuts (Juglans), p. 907-951. In: Moore, J.N. and J.R. Ballington (eds.). Genetic resources of fruit and nut crops. Vol. 2. Acta Hort., Wageningen, The Netherlands.

Mircetich, S.M., G.T. Browne, M.E. Matheron, and B.L. Teviotdale. 1998. Armillaria and Phytophthora root and crown rot diseases, Walnut Production Manual. p. 221-232.

Munnecke, D.E., M.J. Kolbezen, W.D. Wilbur, and H.D. Ohr. 1981. Interactions involved in controlling Armillaria mellea. Plant Dis. 65:384389.

Raabe, R.D. 1979. Testing grape rootstocks for resistance to the oak root fungus. California Plant Pathol. 46:3-4.

Redfern, D.B. and G.M. Filip. 1991. Inoculum and infection, p. 48-61. In: Shaw, C.G. III and G.A. Kile (eds.). Armillaria root disease. U.S. Department of Agriculture Forest Service Agriculture Handbook No. 691, Washington, DC.
Reil, W. 1997. Walnut rootstock evaluation for resistance to Armillaria root rot, Walnut Research Reports 1997. Walnut Marketing Board. p. 109-113.

Rizzo, D.M., E.C. Whiting, and R.B. Elkins. 1998. Spatial distribution of Armillaria mellea in pear orchards. Plant Dis. 82:1226-1231.

Singh, P. 1980. Armillaria root rot: Artificial inoculation and development of the disease in greenhouse. Eur. J. Forest Pathol. 10:420-431.

Teviotdale, B.L. and S. Sibbett. 1999. Armillaria root rot: Role of site preparation and rootstock susceptibility on survival of replanted walnut trees, Walnut Research Reports. California Walnut Board. p. 373-375.

Thomas, H.E., C. Roberts, and A. Amstutz. 1948. Rootstock susceptibility to Armillaria mellea. Phytopathology 38:152-154.

Westfall, P.H., R.D. Tobias, D. Rom, R.D. Wolfinger, and Y. Hochberg. 1999. Multiple comparisons and multiple tests. SAS Institute Inc., Cary, NC. 